This item was submitted to Loughborough's Research Repository by the author.

Items in Figshare are protected by copyright, with all rights reserved, unless otherwise indicated.

\title{
Life cycle assessments of bio-based sustainable polylimonene carbonate production processes
}

PLEASE CITE THE PUBLISHED VERSION

https://doi.org/10.1016/j.spc.2018.03.001

\section{PUBLISHER}

Elsevier $@$ Institution of Chemical Engineers

\section{VERSION}

AM (Accepted Manuscript)

\section{PUBLISHER STATEMENT}

This work is made available according to the conditions of the Creative Commons Attribution-NonCommercialNoDerivatives 4.0 International (CC BY-NC-ND 4.0) licence. Full details of this licence are available at: https://creativecommons.org/licenses/by-nc-nd/4.0/

\section{LICENCE}

CC BY-NC-ND 4.0

\section{REPOSITORY RECORD}

Zhang, Dongda, Ehecatl Antonio del Rio-Chanona, Jonathan Wagner, and Nilay Shah. 2018. "Life Cycle Assessments of Bio-based Sustainable Polylimonene Carbonate Production Processes". figshare. https://hdl.handle.net/2134/36344. 
1 Life cycle assessments of bio-based sustainable polylimonene carbonate production processes

3 Dongda Zhang ${ }^{1,2^{*}}$, Ehecatl Antonio del Rio-Chanona ${ }^{1,2}$, Jonathan L. Wagner ${ }^{2}$, Nilay Shah ${ }^{1,2}$

4

5 1: Centre for Process Systems Engineering, Imperial College London, South Kensington Campus, $6 \quad$ London SW7 2AZ, UK.

7 2: Department of Chemical Engineering, Imperial College London, South Kensington, United $8 \quad$ Kingdom, SW7 2AZ

9

10 *: corresponding author, email: dongda.zhang11 @imperial.ac.uk, tel: 44 (0)7543785283. 
14 Biomass is a promising feedstock for the production of sustainable biopolymers, which could offer a significant reduction of the adverse environmental impacts associated with conventional petroleumbased polymers. To further evaluate their potential, this study investigated the environmental impacts associated with the production of the newly proposed biopolymer polylimonene carbonate. Different feedstocks (citrus waste and microalgae) were selected and a conceptual process design from limonene oxidation to polymer synthesis was completed. Using life cycle assessment, the potential for energy integration and the contributions of individual process sections on the overall process environmental impacts were thoroughly analysed. The results showed, that sustainable polylimonene carbonate synthesis was limited by the use of tert-butyl hydroperoxide as the limonene oxidation agent and consequently, a more environmentally-friendly and energy-efficient limonene oxidation method should be developed. Based on the economic analysis, the polymer cost was estimated to range from $\$ 1.36$ to $\$ 1.51 \mathrm{~kg}^{-1}$, comparable to the costs of petrol-based polystyrene (\$1.2 to $\$ 1.6 \mathrm{~kg}^{-}$ $\left.{ }^{1}\right)$. Moreover, this study found that both feedstock selection and the biowaste treatment method have significant effects on the process environmental impacts, and a carbon negative process was achieved when applying the waste biomass for electricity generation. Therefore, it was concluded that future process designs should combine polymer production with the co-generation of energy from waste biomass.

Keywords: biomass, cradle-to-gate life cycle assessment, polylimonene carbonate, process simulation, economic analysis, sustainable process design. 


\section{INTRODUCTION}

Polymers, such as polylactic acid (PLA), polyethylene terephthalate (PET) or polystyrene, represent an important global commodity, both industrially and domestically. They can adopt a large variety of configurations, with highly specialised properties, making them applicable to a wide range of areas including electronics, healthcare products, toys, packaging materials, and coatings ${ }^{1,2}$. The annual consumption of polymers in the US alone has been estimated at around 31 million tonnes whilst the global production of polymers has exceeded 260 million tonnes since $2009^{3,4}$. In addition, global polymer production between 2009 and 2015 was reported to have increased by up to $20 \%$, indicating a huge potential global market in the future ${ }^{5}$.

To improve the sustainability of the polymer production processes, the last two decades have seen increasing efforts to identify renewable and more environmentally friendly raw materials, particularly biomass, to replace the fossil carbon resources used in traditional polymer synthesis ${ }^{2,6}$. These include agricultural biomass, citrus wastes, and microorganisms, e.g. microalgae and cyanobacteria ${ }^{7-12}$, which have been used for the synthesis of bio-based polymers such as polycarbonates, polyesters, and polyurethane ${ }^{8,13,14}$. To improve the usability of these sustainable feedstocks, new reaction routes have been proposed and compared to the traditional fossil based methods ${ }^{7,15,16}$.

Amongst the newly proposed biopolymer candidates, particular attention has been given to polylimonene carbonate (PLC), produced by the reaction of limonene with carbon dioxide ${ }^{13,16,17}$. PLC has similar properties to polystyrene ${ }^{18}$, one of the major fossil based polymers with a predicted global production of 700,000 tonnes year ${ }^{-1}$ by 2020 and annual sales volume of $\$ 28.7$ billion ${ }^{19}$. As polystyrene is predominantly made from hydrofluorocarbons (HFC-134a), with global warming potentials around 1000 times that of $\mathrm{CO}_{2}{ }^{20}$, there is a great drive to identify more environmentally friendly alternatives. Limonene, required for PLC synthesis, can be obtained from a range of biomass sources, including orange peels, microalgae and other citrus wastes, with an estimated global 
60

61

62

63

64

production of 70,000 to 100,000 tonnes year ${ }^{-1} 17,18,21$, indicating a stable supply for industrial PLC production. Furthermore, as PLC synthesis directly consumes $\mathrm{CO}_{2}$, the overall process has the potential to actively sequester carbon, and therefore be carbon negative (i.e. avoiding greenhouse gas (GHG) emission) ${ }^{13,18}$. Consequently, PLC has great potential to replace polystyrene in the near future.

Previous studies employed life cycle assessments to investigate the potential environmental impacts of limonene production from citrus wastes $^{22}$ and microalgae ${ }^{23}$, whilst a process design for the oxidation of limonene to PLC was published recently ${ }^{18}$. Moreover, optimal reaction conditions for PLC precursor oxidation and monomer polymerisation have been proposed by different studies ${ }^{13,16,24}$. In spite of these achievements, the environmental impacts of the entire PLC production process, ranging from feedstock selection (algae vs. citrus) to downstream PLC synthesis, have not yet been explored, and therefore the process sustainability, economic viability, and industrialisation feasibility are unknown.

To address this open challenge, the current study aimed to design a conceptual PLC production process and conduct a high-level life cycle assessment, facilitating the industrialisation of PLC production at an early stage of the research. In addition, a preliminary economic analysis was carried out to estimate and compare the potential cost of PLC against the price of polystyrene. The next sections will provide a detailed explanation of the design and life cycle assessment of the PLC production process, followed by the results and conclusions discovered in the current research.

\section{METHODOLOGY}

\subsection{Process description}

The overall polylimonene carbonate (PLC) production process can be divided into four distinct operating stages: 1) Production of limonene, 2) Production of the oxidant tert-butyle hydroperoxide (TBHP), 3) Limonene oxidation and 4) PLC synthesis (Figure 1). Moreover, limonene can be 
produced either from citrus waste or engineered microalgae, and each of these sources will be considered in turn.
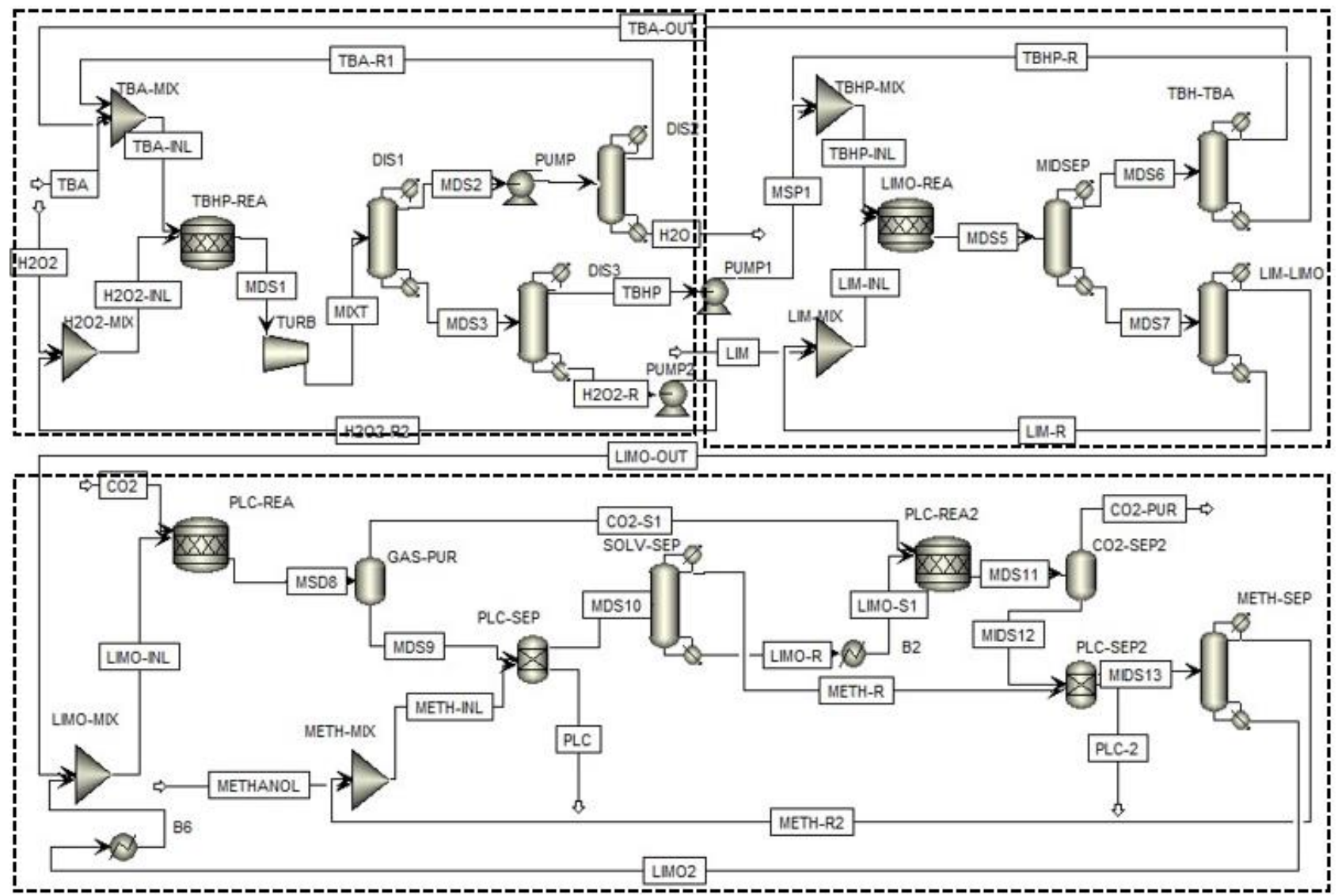

Figure 1: PLC production process (including limonene oxide production (top-left section), TBHP synthesis (top-right section), and PLC production (bottom section)). Heat exchangers are omitted here for convenience. Terminology: DIS - distillation column, MIX - mixer, REA - reactor, PUMP - pumps, SEP - liquid/solid or gas/liquid multi-phase separator, TURB - turbine. SOLV - solvent, METH methanol, MDS - solution mixture, LIM - limonene, LIMO - limonene oxide.

\subsubsection{Limonene production from citrus waste}

Limonene is an important component of all citrus fruits ${ }^{18}$, and particularly abundant in wastes from the orange juice industry $(3.8 \mathrm{wt} \%){ }^{17}$. Consequently current limonene production is mostly focused on these wastes and is usually conducted in two stages. Initially, citrus oils (also called 'cold press orange oil') are extracted from the orange juice during the juicing process, before additional citrus oils ('expressed orange oil') are recovered from the orange peels using steam extraction. Together, 
the collected citrus oils contain $\sim 95 \%$ limonene, which is further purified using either vacuum distillation or winterisation (freezing oils) ${ }^{18,22}$. As this process has already been analysed in detail in the literature, including orange collection and use of the extracted orange peels as cattle feed ${ }^{22}$, it was chosen as the standard route for the production of citrus-based limonene in the current research.

\subsubsection{Limonene production from algae}

An alternative to the conventional, citrus-based limonene production route, is the use of microalgae and cyanobacteria, genetically engineered to produce limonene ${ }^{21,23}$. This route promises substantial advantages (e.g. high growth rate and solar energy utilisation efficiency) over other solar energy and $\mathrm{CO}_{2}$ derived biomass ${ }^{25,26}$. Recently, a detailed process design for algal limonene and energy coproduction was proposed, and the critical limonene productivity, at which the process starts to break even, was identified through process economic analysis ${ }^{27}$. The process considers limonene as the major product, whilst algal biomass waste is anaerobically digested for the production of hydrogen and methane, which are subsequently combusted in gas turbines for electricity generation. This configuration was adapted as the standard route for the production of algal limonene in the present work, to allow comparison against the citrus-based process.

To model algal limonene production, the process was split into five stages (detailed introduction in Supplementary): 1) Algae cultivation in a photobioreactor, 2) limonene recovery via absorption and distillation, 3) algae biomass recovery (including settling, floatation, and electrocoagulation), 4) anaerobic digestion (used for biogas and electricity generation), and 5) wastewater treatment (for water recycle) ${ }^{23,27}$. Previous work tested two different algal limonene productivities; a real-case limonene productivity of $1.8 \mathrm{mg} \mathrm{L}^{-1} \mathrm{~h}^{-1}$ and a much higher productivity value of $55.5 \mathrm{mg} \mathrm{L}^{-1} \mathrm{~h}^{-1} 23$. In contrast, the present study adapted a limonene productivity value of $4.5 \mathrm{mg} \mathrm{L}^{-1} \mathrm{~h}^{-1}$, consistent with the highest algal limonene productivity reported in the literature ${ }^{21}$. 


\subsubsection{Limonene oxide production}

Prior to converting limonene into PLC, it must be oxidised into limonene oxide. This can be achieved using a variety of oxidants such as molecular oxygen gas, hydrogen peroxide and epoxides under specific conditions ${ }^{28-30}$. However, most available data stem from laboratory scale experiments, requiring numerous assumptions to correlate the reaction selectivity and conversion efficiency to large scale systems (linear scale-up) ${ }^{31}$. A particularly promising oxidant is tert-butyl hydroperoxide (TBHP), due to its mild operating conditions (room temperature, 1 bar), high single-pass conversion $(75 \%)$ and selectivity $(88 \%)$ (Equation 1$)^{18}$. Therefore, TBHP was selected as the oxidant for limonene oxide synthesis in the current study.

Initially, limonene and TBHP are fed to the reactor at a molar ratio of 1:1. The reaction is conducted at room temperature and atmospheric pressure in the presence of catalyst (silica dissolved in solvent)

${ }^{18}$. The resulting product mixture containing limonene oxide, tert-butyl alcohol (TBA), and unreacted limonene and TBHP (side reaction is neglected) is sent to a distillation column (MIDSEP) for the separation of TBA and TBHP from limonene and limonene oxide. Further separation of limonene and limonene oxide and of TBA and TBHP is achieved in two additional columns. Eventually, unreacted TBHP and limonene are recycled back to the reactor, limonene oxide is sent to the PLC production stage, and TBA is returned to the TBHP regeneration stage. Heat exchangers are used to pre-heat the product mixture and cool the outlets from the distillation columns.

\subsubsection{Tert-butyl hydroperoxide regeneration}

Although tert-butyl hydroperoxide (TBHP) is a commercially available chemical commodity, the environmental and life cycle impacts of its industrial synthesis routes have not yet been analysed. As the current study aims to conduct the life cycle analysis (LCA) for the entire PLC production process, 


\subsubsection{Polylimonene carbonate production}

Finally, the polymerisation reaction of $\mathrm{CO}_{2}$ and limonene oxide into PLC is conducted in the presence of homogeneous, zinc-based catalysts at pressures of $\sim 7$ bar (100 psi) and at ambient temperature ${ }^{13,18}$, with single-pass limonene oxide conversions of $50 \%$ (Equation 3$)^{18}$.

it is necessary to include the TBHP synthesis in this work. Commercial TBHP production follows one of three different synthesis routes: 1) tert-butyl alcohol (TBA) oxidation by hydrogen peroxide, 2) reaction between peroxymonosulphuric acid and TBA, and 3) auto-oxidation of isobutene with oxygen ${ }^{32}$. During limonene oxidation, TBHP is reduced back into TBA, and consequently, the first two choices are advantageous from the circular economy point of view. Therefore, the limonene oxidation process only requires hydrogen peroxide or peroxymonosulphuric acid, whilst TBA/TBHP act as the electron carrier. As reactions involving peroxymonosulphuric acid may yield an explosive intermediate ${ }^{32}$, the hydrogen peroxide process, which produces only water, represents the safest and most environmentally favourable process overall and was chosen for this study.

TBA oxidation occurs at room temperature and 1 bar in an acidic environment (Equation 2), with a high single-pass TBHP yield (approximately 90\%) ${ }^{33}$. After reaction, the product mixture (unreacted $\mathrm{H}_{2} \mathrm{O}_{2}$ and TBA, TBHP, water) is distilled under vacuum, due to the low heat stability of $\mathrm{H}_{2} \mathrm{O}_{2}{ }^{34}$. After downstream separation, unreacted TBA and $\mathrm{H}_{2} \mathrm{O}_{2}$ (recompressed to 1 bar) are recycled back to the TBA oxidation reactor, whilst TBHP is fed to the limonene oxide production stage, and water is transported to the utility system (to generate steam or cooling water).

$$
\mathrm{H}_{2} \mathrm{O}_{2}+\mathrm{C}_{4} \mathrm{H}_{10} \mathrm{O} \stackrel{\text { rt. } 1 \text { bar, } \mathrm{H}^{+}}{\longrightarrow} \mathrm{H}_{2} \mathrm{O}+\mathrm{C}_{4} \mathrm{H}_{10} \mathrm{O}_{2}
$$


After flashing off excess $\mathrm{CO}_{2}, \mathrm{PLC}$ is precipitated from the product mixture through the addition of methanol ${ }^{18}$. Subsequently, the solvent is removed via distillation and unreacted limonene oxide is passed to a secondary reaction stage to continue the polymerisation process, followed by renewed PLC precipitation with methanol. This two-reaction stage configuration has been adapted to reduce the energy requirements associated with the gas-liquid mixing in the large, primary reactor ${ }^{18}$. Following distillation, unreacted limonene is recycled to the first reactor whilst the methanol phase is sent to a liquid-solid separation tank, for the collection of the final PLC product.

\subsection{Life cycle assessment}

Life cycle assessment (LCA) is a norm-based methodology to estimate the environmental impacts of a specific product over its entire life cycle ${ }^{35}$. It consists of four key steps: goal and scope definition, life cycle inventory, life cycle impact assessment, and interpretation ${ }^{31}$. LCAs can be applied across different system boundaries, such as cradle-to-grave, cradle-to-gate, and gate-to-gate analysis ${ }^{14,23,36}$. Amongst these, cradle-to-gate (from feedstock collection to final production of the investigated product, excluding transportation to the local market) is the most common, as the transportation and end use of the final product are usually similar ${ }^{14}$. As the current work covers the process from the preparation of the raw material (fertilising orange trees or cultivating algae biomass) to the final production of PLC before it is transported to customers, the cradle-to-gate analysis was applied.

\subsubsection{Goal and scopes}

The primary goal of this LCA was to investigate the net $\mathrm{CO}_{2}$ emissions or consumption of the newly proposed biopolymer (PLC) manufacturing process and identify any potential adverse environmental impacts (e.g. ozone and water deletion). In this context, the term "carbon negative" specifically refers to eliminating GHG emission during the product synthesis route. To provide a comprehensive analysis for PLC production at this early stage of research, the LCA covered limonene production from both algal and citrus waste resources. Moreover, although algal biomass was sent for energy 
regeneration in the previous study, in this work to explore the carbon footprint and solar energy utilisation efficiency of each process, two different scenarios were considered for the disposal of waste biomass, namely energy generation via anaerobic digestion ("PLC from algae") and use of biowaste as animal feed ("PLC from algae without electricity").

\subsubsection{System boundaries and function units}

In this study, two sets of LCA boundaries were used: the boundaries between the entire production system (from algae cultivation or citrus plantation to PLC production) and the environment, and the boundaries between each of the four separate processing stages (production of limonene, limonene oxide, TBHP, and PLC). It should be noted, that the supply chain of raw materials and transportation of products were not included in this study. The first boundary set was applied to analyse the environmental impacts of the entire system, whereas the latter set was employed to allow correlation of major environmental burdens to specific processing stages.

The current global production of limonene has been estimated between 70,000 and 100,000 tonnes year $^{-1}{ }^{19}$. Considering its predominant use in other industries (e.g. perfume and food), the present study assumed an annual limonene consumption of 15,000 tonnes for the production of PLC in a single plant, as recommended previously ${ }^{37}$. As a result, the function unit for this LCA was set to the equivalent PLC production (21,600 tonnes) from a single plant.

In addition, in this study methanol is used as a solvent to precipitate PLC, and TBHP is used as the direct oxidant for limonene oxidation. As introduced before, both of them are recycled inside process without being emitted, meaning they are confined in the system. Moreover, their purchase is one-off (other materials have to be supplied continuously) and their required amount is much lower than other chemicals. As a result, it is plausible to exclude the environmental impact of these chemicals in the 
preliminary LCA. However, to verify the validity of this simplification, different cases were designed and compared in this work and presented in Section 3.3.

\subsubsection{Life cycle inventory}

The life cycle inventory was calculated from mass and energy balances. The environmental impacts of limonene production from both citrus wastes and microalgae were previously evaluated in LCA studies ${ }^{23,22} 27$, and were directly adopted in the current study, except for the increased algal limonene productivity of $4.5 \mathrm{mg} \mathrm{L}^{-1} \mathrm{~h}^{-1}$ instead of $1.8 \mathrm{mg} \mathrm{L}^{-1} \mathrm{~h}^{-1}$ as described above (Section 2.1.2). To account for this change, the original inventory was revised by interpolation (shown in Supplementary Information). For the production of limonene oxide, TBHP, and PLC, both mass balances and energy consumptions were estimated through process simulation. LCAs for the production of $\mathrm{H}_{2} \mathrm{O}_{2}$ and TBA, the two starting materials for TBHP synthesis, are available from the Ecoinvent 3.2 database and previous research ${ }^{36}$. Hence, combining this information, allowed the completion of the LCA for the PLC production process. The full inventory from raw materials consumption to PLC production can be found in the Supplementary Information.

\subsubsection{Allocation of by-products}

The previous LCA for limonene production from citrus feedstocks stated that only $1 \%$ of the environmental impacts of the process should be allocated to limonene (economic based), as it is a waste-derived by-product with a much lower production volume than orange juice, whilst the remaining citrus waste after limonene production is sold as cattle feed ${ }^{22}$. This is different to limonene production from the algae-based process, which has been particularly designed for the co-production of biomass and limonene ${ }^{23}$. In this case, the allocation factor for limonene was set between $64 \%$ and $98 \%$ according to the algal limonene productivity $\left(1.8 \mathrm{mg} \mathrm{L}^{-1} \mathrm{~h}^{-1}\right.$ to $\left.55.5 \mathrm{mg} \mathrm{L}^{-1} \mathrm{~h}^{-1}\right)$, based on the economic value of limonene and biomass residue. As the assumed limonene productivity in the present study was $4.5 \mathrm{mg} \mathrm{L}^{-1} \mathrm{~h}^{-1}$, the allocation factor was increased to $66 \%$ by linear interpolation. 
Hence, the remaining environmental impacts of $34 \%$ was allocated to the biomass waste which was either anaerobically digested for electricity generation or sold directly as animal feed. Although the electricity generated from the algae biomass could be used internally, this would be inefficient as the PLC synthesis requires mostly lower grade heat energy. Consequently, the generated electricity was fed into the electricity grid instead, whilst the heating requirements were met using industrial steam. As the only by-product from the limonene oxidation and PLC production is water, the environmental impacts associated with these stages are fully allocated to PLC.

\subsection{Impact assessment methodology}

The production stages for limonene oxide, TBHP and PLC were simulated in Aspen Plus V9 to estimate both the energy consumption and mass balances for each process section. In addition, the models were used to evaluate the potential for energy integration to reduce the heating and cooling utilities, and obtain estimates for the process capital and operation costs. LCA was performed in Simapro 8.1, using the Ecoinvent 3.2 LCA database and ReCiPe Midpoint method. This method has been widely applied in previous studies ${ }^{22,38}$, and has the advantage of breaking down environmental impacts into specific criteria. The criteria chosen for this study were 'climate change', 'ozone depletion', 'terrestrial acidification', 'freshwater eutrophication', 'human toxicity', 'particulate matter formation', 'terrestrial and freshwater ecotoxicity', 'agricultural land occupation' and 'water and fossil depletion', all of which are commonly used in the literature ${ }^{22,38}$.

\section{RESULTS AND DISCUSSION}

\subsection{Process simulation results}

The modelling results for the PLC production process (from limonene oxide synthesis to PLC production) are presented in Table 1 . These mass balance and energy consumption data form the life cycle inventory for this study. Electricity is mainly used in the utility system and pump system. Moreover, the results includes the energy consumption data after process energy integration. 
Table 1: Process simulation result for the production of $21.6 \mathrm{kt}$ PLC (1 function unit). "Heat integrated" and "Cooling integrated" represent the external energy required for heating and cooling after process energy integration.

\begin{tabular}{|c|c|c|c|c|}
\hline & \multicolumn{4}{|c|}{ Limonene oxide production section } \\
\hline \multirow{2}{*}{ Flow rate } & Limonene & THBP & Limonene oxide & TBA \\
\hline & $1764.7 \mathrm{~kg} \mathrm{~h}^{-1}$ & $1164.8 \mathrm{~kg} \mathrm{~h}^{-1}$ & $1972.3 \mathrm{~kg} \mathrm{~h}^{-1}$ & $957.2 \mathrm{~kg} \mathrm{~h}^{-1}$ \\
\hline \multirow{4}{*}{ Energy use } & Heat (steam) & Heat integrated & Cooling & Cooling integrated \\
\hline & $4.20 \mathrm{MW}$ & $3.24 \mathrm{MW}$ & $5.15 \mathrm{MW}$ & $4.18 \mathrm{MW}$ \\
\hline & \multicolumn{4}{|c|}{ Electricity: $633.6 \mathrm{~kW}$ (143 kW after energy integration) } \\
\hline & \multicolumn{4}{|c|}{ TBHP production section } \\
\hline \multirow{2}{*}{ Flow rate } & $\mathrm{H}_{2} \mathrm{O}_{2}$ & TBA & $\mathrm{H}_{2} \mathrm{O}$ & TBHP \\
\hline & $439.3 \mathrm{~kg} \mathrm{~h}^{-1}$ & $957.2 \mathrm{~kg} \mathrm{~h}^{-1}$ & $232.2 \mathrm{~kg} \mathrm{~h}^{-1}$ & $1164.3 \mathrm{~kg} \mathrm{~h}^{-1}$ \\
\hline \multirow{3}{*}{ Energy use } & Heat (steam) & Heat integrated & Cooling & Cooling integrated \\
\hline & $2.66 \mathrm{MW}$ & $2.60 \mathrm{MW}$ & $2.81 \mathrm{MW}$ & $2.76 \mathrm{MW}$ \\
\hline & \multicolumn{4}{|c|}{ Electricity: $1040 \mathrm{~kW}$ (949 kW after energy integration) } \\
\hline & \multicolumn{4}{|c|}{ PLC production section } \\
\hline \multirow{2}{*}{ Flow rate } & Methanol & Limonene oxide & $\mathrm{CO}_{2}$ & PLC \\
\hline & $833.0 \mathrm{~kg} \mathrm{~h}^{-1}$ & $1927.8 \mathrm{~kg} \mathrm{~h}^{-1}$ & $585.2 \mathrm{~kg} \mathrm{~h}^{-1}$ & $2542.0 \mathrm{~kg} \mathrm{~h}^{-1}$ \\
\hline \multirow{3}{*}{ Energy use } & Heat (steam) & Heat integrated & Cooling & Cooling integrated \\
\hline & $1.95 \mathrm{MW}$ & $1.80 \mathrm{MW}$ & $0.17 \mathrm{MW}$ & $10.1 \mathrm{KW}$ \\
\hline & \multicolumn{4}{|c|}{ Electricity: $5.65 \mathrm{~kW}(0.35 \mathrm{~kW}$ after energy integration) } \\
\hline
\end{tabular}

\subsection{Effect of limonene source and biomass use on process environmental impacts}

To explore the effect of the limonene source (citrus waste and algal biomass) and use of waste biomass (cattle feed or electricity production) on the environmental impacts of the PLC production process, three scenarios were selected for comparison (Figure 2). The two scenarios using biomass 

$\mathrm{kg}\left(\mathrm{CO}_{2}\right.$ eq. $) \mathrm{kg}^{-1}$ (PLC), for the citrus and algae based processes, respectively.

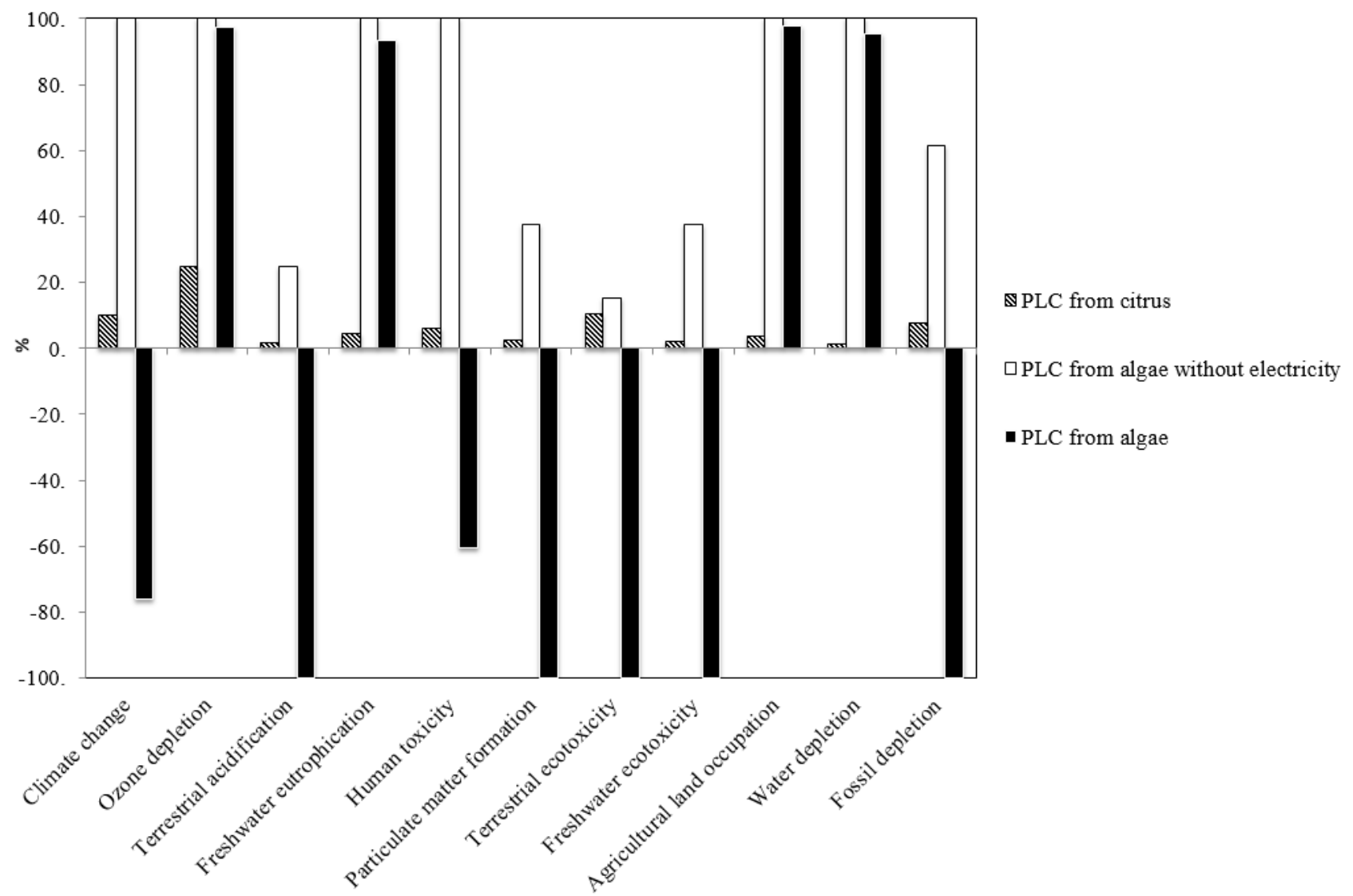

Figure 2: Effect of feedstock and use of biowaste on LCA results (without energy integration and accounting for recycled chemicals) for PLC production process. "PLC from citrus waste" and "PLC from algae without electricity" denote processes where biomass is sold as animal feed, and "PLC from algae" denotes the process where algae biomass is used for energy generation.

In contrast, combining limonene production with energy generation from the algal residue resulted in a carbon negative process together with mostly environmentally favourable indicators (negative values in 7 of 11 categories). This finding can be attributed to the high amount of recoverable solar energy stored inside the biomass, previously estimated at $109.2 \mathrm{MJ} \mathrm{kg}^{-1}$ (PLC), which greatly exceeds the energy requirements of the PLC production process (approximately $22.0 \mathrm{MJ} \mathrm{kg}^{-1}$ (PLC), mainly heat) ${ }^{23}$. Hence, from the energy balance point of view, recovering this energy through the combined anaerobic digestion / electricity generation process, allows the exporting of excess electricity to the 
grid, displacing carbon-based electricity (although in this study industrial steam is directly used for PLC synthesis, and the electricity required for PLC synthesis is negligible compared to that generated from anaerobic digestion). This is not possible, however, when the biomass is sold as animal feed, as the stored solar energy remains unused. Consequently, the system energy demands must be met with alternative, fossil resources, increasing the net carbon emissions of the process.

When comparing the citrus- and algae-derived PLC processes, the latter performs worse in terms of water depletion, land occupation and ozone depletion, regardless of the biomass treatment method. Considering the ethical implications of diverting land and water for fuel generation, these results appear to favour limonene from citrus wastes over algal limonene for PLC production. Nonetheless, it is important to consider the different allocation factors used during the evaluation of these processes. Limonene from citrus waste is considered as a by-product with an allocation factor of only $1 \%$, while limonene from algae was allocated $66 \%$. It is therefore unsurprising that citrus derived limonene is less water or land intensive than algae based limonene. However, as the demand for limonene increases in the future, its allocation factor to the citrus-based process could increase, increasing the associated environmental impacts. For instance, from the current LCA study, it was estimated that increasing the limonene allocation factor to $10 \%$ for citrus derived PLC, results in the same climate change and fossil fuel depletion impacts as the algae derived PLC scenario (without energy generation).

\subsection{Effect of solvent and oxidant used during PLC production}

To evaluate the effect of the solvent (methanol) and oxidant (TBHP) on the overall life cycle impacts of the PLC process, the system was modelled with and without these chemicals (Figure 3). It was assumed, that all the TBHP required during the first year was purchased externally, whilst in all subsequent years, $90 \%$ of the required TBHP was regenerated internally from TBA, requiring only $10 \%$ of new TBHP. The results show that methanol has a very minor effect on the system, whereas 
the inclusion of TBHP significantly increases the impacts on climate change, human toxicity, and ecotoxicity. For instance, for the citrus-based process the climate change and human toxicity impacts increase by $156.7 \%$ and $1603.4 \%$, respectively, even though the use and replacement of lost TBHP is much lower than for any of the other feedstocks.

In the case of algal PLC production, including TBHP production changes the values for human toxicity, terrestrial ecotoxicity and freshwater ecotoxicity from negative to positive, indicating a change from a net positive to a net detrimental environmental impact. This clearly suggests that even though TBHP/TBA is recycled internally within the process, and only employed as an electron carrier for the redox reaction between limonene and hydrogen peroxide, its current external synthesis route (TBA is a co-product from commercial propylene oxide synthesis ${ }^{36}$ ) could significantly aggravate the environmental impacts of the PLC production process, depending on how much is actually consumed in the process. As a result, more environmentally friendly routes should be developed for the synthesis of TBHP/TBA, whilst more research effort should be focused on the direct reaction between limonene and hydrogen peroxide.

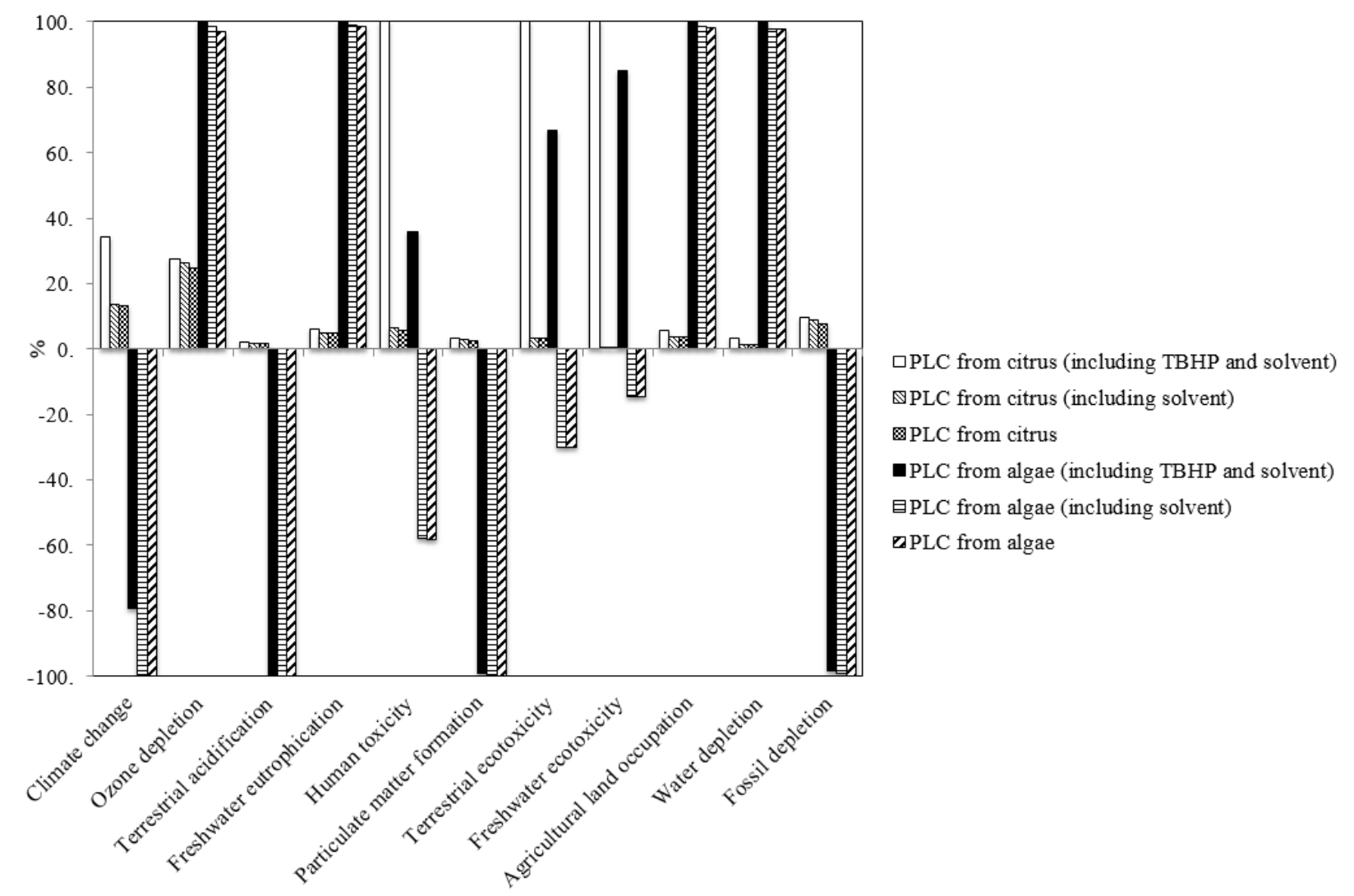


Figure 3: Effect of solvent (methanol) and oxidant (TBHP) on LCA results (without energy 347 integration) for PLC production process.

\subsection{Effect of energy integration on PLC production process}

For many chemical processes, heat exchange between hot and cold streams is an effective method of reducing the energy requirements of the utility system. Therefore, the current research conducted a preliminary estimation of the energy integration potential of the PLC production process (Table 1).

353 This resulted in total energy savings (heat and electricity) of $20.8 \%$, mostly associated with the 354 reduction of electricity used for the recycling of cooling water in the limonene oxide production section (77.4\%) and PLC production section (93.8\%). Except for the limonene oxide production section, energy integration had little impact on the heat requirements (steam) of the PLC production process, as most of the reactions take place at room temperature, and their product mixtures are easily separated by distillation.

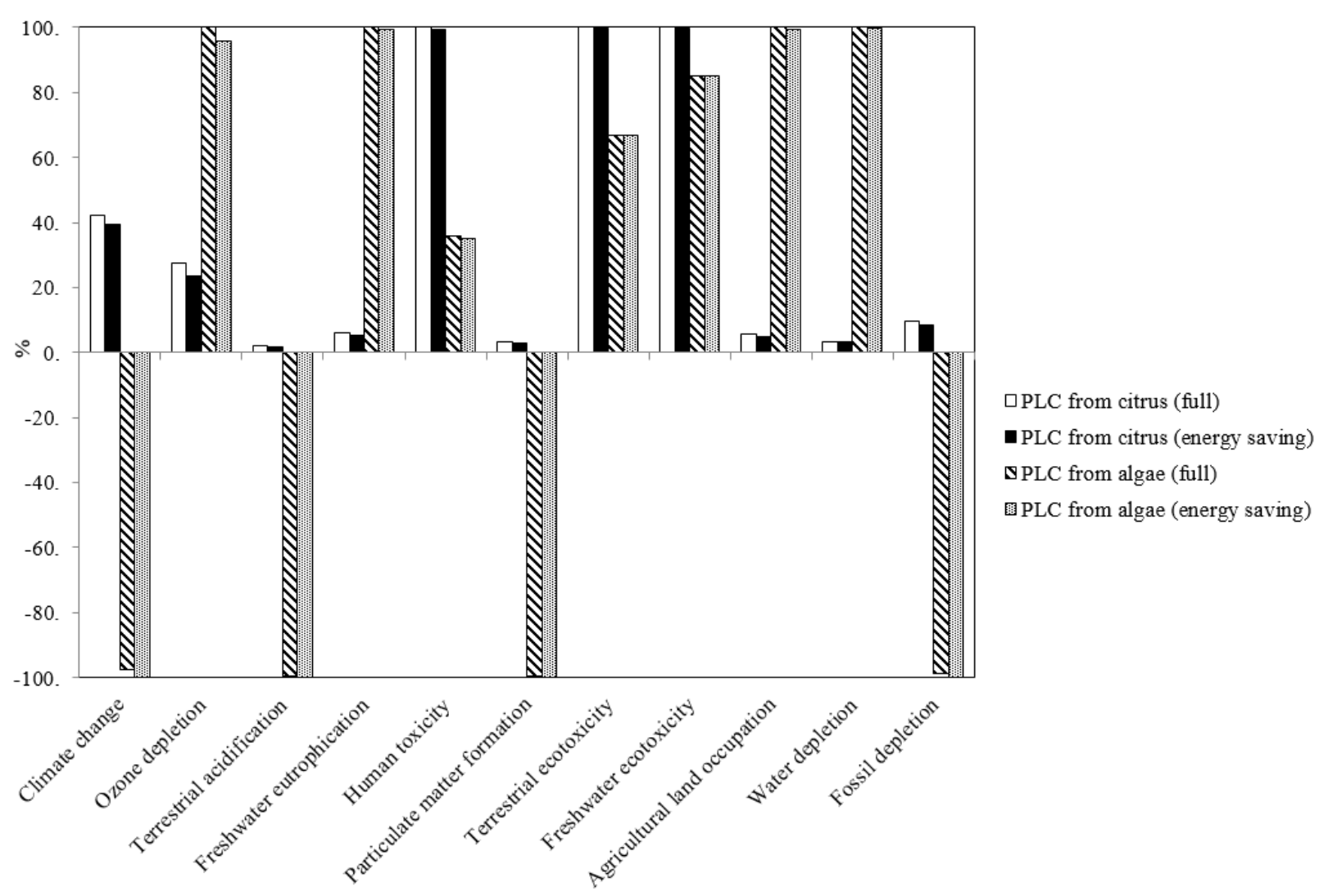


Figure 4: Effect of energy integration on LCA results (including impacts of recycled chemicals) for PLC production process. "PLC from citrus (full)" and "PLC from algae (full)" represent results without energy integration; "PLC from citrus (energy saving)" and "PLC from algae (energy saving)" represent the cases where energy integration has been included.

Including the energy integration savings within the life cycle assessment results in small improvements on climate change $(6.2 \%)$ and ozone depletion (15.2\%), but has a marginal impact on the other environmental categories, regardless of limonene feedstock (Figure 4). This indicates that energy integration may not be an effective method of improving the environmental-friendliness of the PLC process, whilst increasing the capital investment due to the addition of heat exchangers and other auxiliary equipment. However, it is important to stress that in the current process most of the reactions are room temperature, limiting the potential for energy integration to the cooling water system. As cooling water does not represent a significant environmental burden, energy integration has no significant impact on the overall environmental impacts of the process. In contrast, for processes involving high-temperature reactions, the findings may be different, and energy integration may still represent an effective solution.

\subsection{Contribution of individual process sections to overall environmental impacts of PLC process}

To discover the contribution of each individual process section to the overall environmental impact of the PLC process, the impacts were evaluated separately for each processing stage (Figure 5). For the citrus based PLC production process, limonene production carries the lowest environmental burden (in most cases less than 10\%), indicating that the use of biowaste for the production of biorenewable precursors could offer a sustainable processing route. 

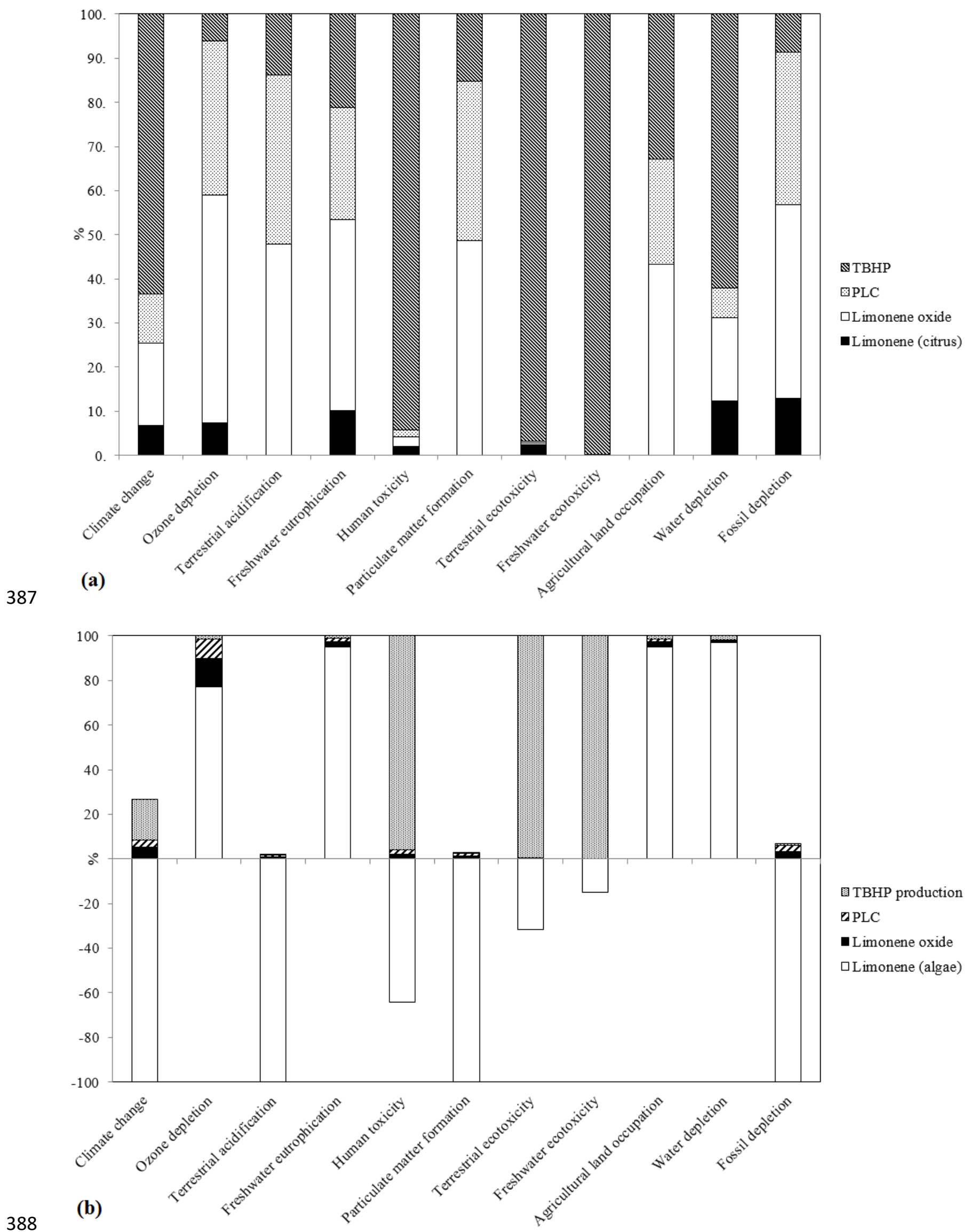

389 Figure 5: Contribution of individual process sections to the overall environmental impact of the PLC 
process (after energy integration and consideration for recycled chemicals). (a): citrus derived PLC production process. (b): algae derived PLC production process.

Consistent with the results from section 3.3, the TBHP regeneration section makes a major contribution to the overall system environmental impacts, even though the consumption of externally supplied TBHP is much lower than for the other chemicals. This result emphasizes the need to develop more environmentally friendly reaction pathways that eliminate the use of TBHP. The production of limonene oxide has the second highest environmental impacts, in many cases more than twice the impacts attributed to the PLC production section. This can be related to the high energy requirements of this section, representing $58 \%$ and $47 \%$ of the total respective electricity and heat consumption of the PLC production process. Consequently, it is recommended that more energyefficient synthesis routes should be developed for the limonene oxide production step.

Different to the citrus derived PLC production process, the PLC production and limonene oxide production sections make a relatively minor contribution to the algae derived PLC processes. Although the impacts of TBHP production are still significant, it is noteworthy that limonene production carries large environmental burdens in a number categories, particularly ozone depletion, land occupation, and water depletion. Once again, the difference to the citrus based process can be attributed to the much higher factor allocated to limonene production, as it is the primary economic driver for this scenario. Nonetheless, the results also show great positive impacts associated with algal limonene (negative values), in categories such as climate change and fossil resource depletion. Recall that in this process, biomass waste is sent to anaerobic digestion for energy generation, and more energy is produced than required for the whole PLC production process. As a result, the net fossil fuel consumption is negative and no $\mathrm{CO}_{2}$ is emitted to the environment. It should be emphasized, however, that the present study does not include the supply chain of the raw materials or 
transportation of products. The above result should therefore be verified further using entire life cycle assessments.

\subsection{Process economic analysis}

To assess the financial viability of the citrus- and algae-based PLC production routes, the capital and operating costs were estimated in Aspen Plus V9 for a single PLC production plant (Table 2). Prices for the raw materials were obtained from manufacturer websites and recent studies $\left(\mathrm{CO}_{2}\right.$ price was assumed to be zero as it is a general industrial waste which can be collected from different processes at little cost) ${ }^{18,27}$. It can be seen that the cost of PLC ranges from $\$ 1.36 \mathrm{~kg}^{-1}$ for the citrus-based route to $\$ 1.51 \mathrm{~kg}^{-1}$ for the algal route. Whilst these values exceed the market price for polyethylene $(\$ 0.91$ $\left.\mathrm{kg}^{-1}\right)$, they fall within the price range of polystyrene ( $\$ 1.2$ to $\left.\$ 1.6 \mathrm{~kg}^{-1}\right)$, a traditional commercial polymer with similar properties to PLC but based on conventional fossil resources. Consequently, based on the results from the life cycle assessment and process economic analysis, it can be concluded that the proposed process has great potential to replace fossil based polystyrene with biomass derived PLC.

Table 2: Results from economic analysis of the PLC production processes

\begin{tabular}{|c|c|c|c|}
\hline \multicolumn{4}{|c|}{ Process capital and operating cost (21.6 kton PLC annually) } \\
\hline & THBP production & Limonene oxide production & PLC production \\
\hline Capital cost & $\$ 1.15$ million & $\$ 5.87$ million & $\$ 5.62$ million \\
\hline Operating cost & $\$ 0.33$ million $\mathrm{yr}^{-1}$ & $\$ 1.80{\text { million } \mathrm{yr}^{-1}}^{-1}$ & $\$ 1.69{\text { million } \mathrm{yr}^{-1}}^{-1}$ \\
\hline \multicolumn{4}{|c|}{ Raw material price $\left(\$ \mathrm{~kg}^{-1}\right)^{18,27}$} \\
\hline Limonene (citrus) & 1.35 & Hydrogen peroxide & 0.40 \\
\hline Limonene (algae) & 1.57 & Methanol & 0.30 \\
\hline Tert-butyl alcohol & 1.48 & $\mathrm{CO}_{2}$ & 0.0 \\
\hline \multicolumn{4}{|c|}{$\mathrm{PLC}$ cost $\left(\$ \mathrm{~kg}^{-1}\right)$} \\
\hline PLC from citrus & 1.36 & PLC from algae & 1.51 \\
\hline
\end{tabular}




\section{Conclusion}

433 The current study designed and assessed a process for the production of the polystyrene substitute PLC from biomass-derived limonene. Particular attention was given to the source of limonene (citrus waste or engineered algae), the use of waste biomass (animal feed or electricity generation) and the potential of energy integration, to minimise the life cycle impacts of the process.

Compared to citrus waste, adverse life cycle impacts of algal limonene production were significantly enhanced, particularly with respect to ozone depletion, agricultural land use and water depletion. This could be mostly attributed to the high allocation factor given to limonene production from the algal route $(66 \%)$ compared to the citrus route $(1 \%)$. At the same time, algal limonene production offers a number of significant advantages, most notably the potential for gasification and electricity generation from waste biomass, which was found to significantly outweigh the energy requirements of the process. Consequently, the algal route, incorporating electricity production, had a substantial net positive impact on a number of life cycle categories, most notably climate change and fossil resource depletion. This highlights the importance of identifying the most effective ways to maximise the utilisation efficiency of the huge amount of solar energy stored inside biowaste.

By analysing the individual stages of the PLC production process, it was found that the use of TBHP as an electron carrier for the redox reaction between limonene and hydrogen peroxide had a significant negative impact on the overall process despite its low quantities compared to the other reaction chemicals. More research should therefore be focused on the development of alternative

453 limonene oxidation routes, such as applying hydrogen peroxide directly, as well as quantifying the actual TBHP losses from the process. 
456 Interestingly, energy integration had only a limited positive impact on the overall life cycle 457 assessment, which was attributed to the ambient reaction temperatures employed in this process. 458 Finally, cost estimates for PLC production $\left(\$ 1.36 \mathrm{~kg}^{-1}\right.$ to $\left.\$ 1.51 \mathrm{~kg}^{-1}\right)$ were comparable to the cost of 459 polystyrene, and it was therefore concluded that the proposed process has great potential to replace 460 fossil based polystyrene with biomass derived PLC.

462 Acknowledgement

463 This research is supported by the EPSRC project under grant EP/L017393/1, "Sustainable Polymers". 464

\section{References}

466 1. Hottle TA, Bilec MM, Landis AE. Sustainability assessments of bio-based polymers. Polym 467 Degrad Stab. 2013;98(9):1898-1907.

2. Zhu Y, Romain C, Williams CK. Sustainable polymers from renewable resources. Nature. 2016;540(7633):354-362.

3. Zhang D, del Rio-Chanona EA, Shah N. Screening Synthesis Pathways for Biomass-Derived Sustainable Polymer Production. ACS Sustain Chem Eng. April 2017:acssuschemeng.7b00429.

4. Thompson RC, Swan SH, Moore CJ, vom Saal FS. Our plastic age. Philos Trans R Soc B Biol Sci. 2009;364(1526):1973-1976.

5. Han J. Process systems engineering studies for catalytic production of bio-based platform molecules from lignocellulosic biomass. Energy Convers Manag. 2017;138:511-517.

6. Miller SA. Sustainable Polymers: Opportunities for the Next Decade. ACS Macro Lett. 2013;2(6):550-554.

478 7. Darensbourg DJ, Chung W-C, Arp CJ, Tsai F-T, Kyran SJ. Copolymerization and Cycloaddition Products Derived from Coupling Reactions of 1,2-Epoxy-4-cyclohexene and 
482 8. Winkler M, Romain C, Meier MAR, Williams CK. Renewable polycarbonates and polyesters from 1,4-cyclohexadiene. Green Chem. 2015;17(1):300-306.

9. Isikgor FH, Becer CR. Lignocellulosic biomass: a sustainable platform for the production of bio-based chemicals and polymers. Polym Chem. 2015;6(25):4497-4559.

10. Gandini A, Lacerda TM, Carvalho AJF, Trovatti E. Progress of Polymers from Renewable

Resources: Furans, Vegetable Oils, and Polysaccharides. Chem Rev. 2016;116(3):1637-1669.

11. Wang X, Ort DR, Yuan JS. Photosynthetic terpene hydrocarbon production for fuels and 489 chemicals. Plant Biotechnol J. 2015;13(2):137-146.

12. Paggiola G, Stempvoort S Van, Bustamante J, Barbero JMV, Hunt AJ, Clark JH. Can bio-

13. Hauenstein O, Reiter M, Agarwal S, Rieger B, Greiner A. Bio-based polycarbonate from based chemicals meet demand? Global and regional case-study around citrus waste-derived limonene as a solvent for cleaning applications. Biofuels, Bioprod Biorefining. 2016;10(6):686-698. limonene oxide and CO 2 with high molecular weight, excellent thermal resistance, hardness and transparency. Green Chem. 2016;18(3):760-770.

14. von der Assen N, Bardow A. Life cycle assessment of polyols for polyurethane production using CO2 as feedstock: insights from an industrial case study. Green Chem. 2014;16(6):3272.

15. Ellis WC, Jung Y, Mulzer M, Di Girolamo R, Lobkovsky EB, Coates GW. Copolymerization of $\mathrm{CO} 2$ and meso epoxides using enantioselective $\beta$-diiminate catalysts: a route to highly isotactic polycarbonates. Chem Sci. 2014;5(10):4004.

16. Peña Carrodeguas L, González-Fabra J, Castro-Gómez F, Bo C, Kleij AW. Al III -Catalysed Formation of Poly(limonene)carbonate: DFT Analysis of the Origin of Stereoregularity. Chem - A Eur J. 2015;21(16):6115-6122.

17. Ciriminna R, Lomeli-Rodriguez M, Demma Carà P, Lopez-Sanchez JA, Pagliaro M. Limonene: a versatile chemical of the bioeconomy. Chem Commun. 2014;50(97):15288-15296.

18. Dalaeli J, Fogle C, Yang J. Polymers from Oranges: Design and Feasibility of Polymer 
19. Wood L. Global Polystyrene Market - By Application, Regions - Market Size, Demand Forecasts, Industry Trends and Updates (2014-2020). Dublin; 2016.

20. U.S. Environmental Protection Agency. Global Warming Potentials (GWP) of ODS Substitutes.; 2016.

21. Davies FK, Work VH, Beliaev AS, Posewitz MC. Engineering Limonene and Bisabolene Production in Wild Type and a Glycogen-Deficient Mutant of Synechococcus sp. PCC 7002.

22. Roberts G. Life Cycle Assessment - Renewable and Sustainable Citrus Oils Final Report. Chicago; 2012.

23. Jahandideh A, Johnson TJ, Esmaeili N, et al. Life cycle analysis of a large-scale limonene production facility utilizing filamentous N 2 -fixing cyanobacteria. Algal Res. 2017;23:1-11.

24. Hauenstein O, Agarwal S, Greiner A. Bio-based polycarbonate as synthetic toolbox. Nat Commun. 2016;7:11862.

25. del Rio-Chanona EA, Manirafasha E, Zhang D, Yue Q, Jing K. Dynamic modeling and optimization of cyanobacterial C-phycocyanin production process by artificial neural network. Algal Res. 2016;13:7-15.

26. Zhang D, Chanona EAD-R, Vassiliadis VS, Tamburic B. Analysis of green algal growth via dynamic model simulation and process optimization. Biotechnol Bioeng. 2015;112(10).

27. Johnson TJ, Jahandideh A, Johnson MD, et al. Producing next-generation biofuels from filamentous cyanobacteria: An economic feasibility analysis. Algal Res. 2016;20:218-228.

28. Bonon AJ, Kozlov YN, Bahú JO, Filho RM, Mandelli D, Shul'pin GB. Limonene epoxidation with $\mathrm{H} 2 \mathrm{O} 2$ promoted by A12O3: Kinetic study, experimental design. J Catal. 2014;319:71-86.

29. Pena A, Veiga S, Sapelli M, et al. Limonene oxidation by molecular oxygen under solventfree conditions: the influence of peroxides and catalysts on the reaction rate. React Kinet Mech Catal. 2012;107(2):263-275. 
534 30. Casuscelli SG, Crivello ME, Perez CF, et al. Effect of reaction conditions on limonene 535 epoxidation with $\mathrm{H} 2 \mathrm{O} 2$ catalyzed by supported Keggin heteropolycompounds. Appl Catal A $536 \quad$ Gen. 2004;274(1-2):115-122.

537 31. Montazeri M, Eckelman MJ. Life Cycle Assessment of Catechols from Lignin 538 Depolymerization. ACS Sustain Chem Eng. 2016;4(3):708-718.

539 32. Sanchez J, Myers TN. Peroxides and Peroxide Compounds, Organic Peroxides. In: Kirk$540 \quad$ Othmer Encyclopedia of Chemical Technology. Hoboken, NJ, USA: John Wiley \& Sons, Inc.; 2000 .

542 33. Bell E, Vaughan W. Preparation of organic hydroperoxides. 1953:6.

543 34. Hurd C, Puterbaugh M. CONCENTRATION OF HYDROGEN PEROXIDE SOLUTIONS. $544 \quad$ Evanston; 1930.

545 35. Yates MR, Barlow CY. Life cycle assessments of biodegradable, commercial biopolymers546 A critical review. Resour Conserv Recycl. 2013;78:54-66.

547 36. Ghanta M, Fahey DR, Busch DH, Subramaniam B. Comparative Economic and Environmental Assessments of H 2 O 2 -based and Tertiary Butyl Hydroperoxide-based Propylene Oxide Technologies. ACS Sustain Chem Eng. 2013;1(2):268-277.

550 37. Kong Q, Shah N. An optimisation-based framework for the conceptual design of reaction$551 \quad$ separation processes. Chem Eng Res Des. 2016;113:206-222.

552 38. Keller H, Rettenmaier N, Reinhardt GA. Integrated life cycle sustainability assessment - A 553 practical approach applied to biorefineries. Appl Energy. 2015;154:1072-1081. 